\title{
Enunciación
}

\section{Las modalidades de lectura: un tema para reflexionar sobre la práctica docente}

\author{
The modalities of reading: a topic to reflect on the teaching practice \\ Dylan Ferney Poveda Vargas ${ }^{*}$,, Videsmir Benavides Ramírez ${ }^{* *}$, \\ Stefannith Ospina Bocanegra ${ }^{* * *} \mathbb{E}$
}

\section{Resumen}

El artículo tiene como propósito presentar los resultados de la intervención que se llevó a cabo con profesores del área de Humanidades de un colegio del suroccidente de Bogotá, en la localidad de Bosa, en torno a la lectura y sus modalidades, con el objetivo de actualizarlos teóricamente. Para tal fin, se optó por una metodología cualitativa, donde se diseñaron e implementaron talleres, teniendo como punto de partida las concepciones de los maestros en relación con esta acción discursiva. El reporte de caso concluye con hallazgos que evidencian que se cumplió con el objetivo, en cuanto a que los docentes transformaron sus prácticas pedagógicas en relación con las dos categorías trabajadas en los talleres.

Palabras clave: lectura, modalidades de lectura.

\begin{abstract}
This article aims to present the results of the intervention about reading and its modalities carried out with a group of teachers from the Humanities Department of a school in the town of Bosa, in the Southwest of Bogota city. The purpose was to qualify them in a theoretical aspect. To this end, a qualitative methodology was chosen, and a series of didactic workshops were designed and implemented, taking as a starting point the teachers' conception related to this discursive action. The case report is concluded with the findings that demonstrate the achievement of this objective, since the teachers transformed their pedagogical practices regarding the two categories worked on the workshops.
\end{abstract}

Keywords: reading, reading modalities.

\footnotetext{
* Magíster en Pedagogía de la Lengua Materna Universidad Distrital Francisco José de Caldas. Docente SED, San Pedro Claver, Bogotá. Correo electrónico: dylan. vargas18@gmail.com

** Licenciada en Literatura y Lingüística de la Universidad La Gran Colombia. Magíster en Pedagogía de la Lengua Materna, Universidad Distrital Francisco José de Caldas. Docente SED Germán Arciniegas, Bogotá. Correo electrónico: videsmir@gmail.com

*** Licenciada en Educación Básica con énfasis en Humanidades: Español e Inglés de la Universidad Pedagógica Nacional. Maestrante en Pedagogía de la Lengua Materna, Universidad Distrital Francisco José de Caldas. Docente SED Guillermo Cano Isaza, Bogotá. Correo electrónico: stefannithospina@gmail.com
}

Cómo citar: Poveda Vargas, D. F., Benavides Ramírez, V. y Ospina Bocanegra, S. (2020). Las modalidades de lectura: un tema para reflexionar sobre la práctica docente. Enunciación, 25(2), 262-271. https://doi.org/10.14483/22486798.15470

Artículo recibido: 29 de octubre de 2019; aprobado: 26 de agosto de 2020 


\section{Introducción}

La lengua fue tomada como un objeto de estudio desde principios del siglo pasado por De Saussure (1974), quien la definió como "un producto social de la facultad del lenguaje y un conjunto de convenciones necesarias, adoptadas por el cuerpo social para permitir el ejercicio de esta facultad en los individuos" (p. 22); es decir, es tomada como un sistema con unas finalidades sociales desarrolladas por individuos. Posteriormente, Noam Chomsky daría un viraje en la materia, puesto que, con la Gramática generativa transformacional, logró estudiar el sistema desde las estructuras tanto superficiales como profundas, lo que significa que a partir de la categorización de la lengua posibilita un análisis estructural. Por ende, "el niño, como el lenguaje, posee una capacidad creativa, generativa, que le permite, con unas pocas estructuras, producir las oraciones de su lengua" (citado por Bernal, 1984, p. 224), en otras palabras, la lengua es un sistema generacional. En este sentido, la lectura se asoció por mucho tiempo a dicha mirada lingüística, lo que implicó concebirla desde una mirada sistémica y convencional como un acto de decodificación de signos lingüísticos que permite llegar a un determinado mensaje.

Sin embargo, posteriormente se presentan unas miradas más amplias con respecto a los contextos, a lo social; autores como: Vygotsky (1995), Hymes (1972), Halliday (1998), serían quienes ampliarían las miradas de Saussure y Chomsky, considerando la relación directa entre pensamiento y lenguaje, y comprendiéndolo bajo una mirada social. Asimismo, se entiende que la "relación del lenguaje y el sistema social no solo es una relación de expresión, sino una dialéctica natural más compleja en que el lenguaje simboliza activamente al sistema social, creándolo y siendo creado por él" (Halliday, 1998, p. 237), lo que necesariamente sostiene un vínculo directo entre la lengua y lo social. Para este momento, la lectura se entiende como una habilidad comunicativa que tiene un sentido social, por tanto, sus fines son distintos y la escuela busca cómo direccionar los procesos lectores a situaciones sociales reales propias del contexto, que impliquen las necesidades de los estudiantes.

No obstante, desde la perspectiva semiótica, la cual adopta el presente documento, un texto no solamente se refiere a una serie de signos lingüísticos sistémicamente organizados, sino que la imagen y el sonido entran a desempeñar un papel determinante, puesto que también son considerados textos y por ende susceptibles de ser leídos. En este sentido, la lectura no se limita a la decodificación de signos lingüísticos, sino que su mirada es más amplia.

Por lo anterior, el presente reporte de caso tiene como finalidad presentar los resultados de la propuesta de intervención didáctica trabajada por Graile (Grupo Académico de Investigación en Lectura), con un colectivo de profesores de un colegio ubicado en el suroccidente de la ciudad de Bogotá, con el objetivo de llevar a cabo una actualización teórica sobre la lectura, debido a que a partir de un primer taller diagnóstico exploratorio sobre las concepciones de lectura se determinó que predomina la lingüística, es decir que los docentes conciben la lectura solo desde la decodificación de signos lingüísticos. Por lo anterior, el Graile centra sus intereses en dar a conocer otras modalidades de lectura que promuevan experiencias distintas, tanto en estudiantes como en docentes, y que por ende sean significativas.

\section{Referentes conceptuales}

\section{Concepción de lectura}

Para efectos de la intervención, la lectura es vista desde la perspectiva semiótica. De esta manera, es necesario mencionar lo que plantea Bobes sobre el proceso semiótico. Este debe entenderse como aquel "que brinda al individuo la posibilidad de generar significado y sentido" (citado por Santiago, Castillo y Ruiz, 2005, p. 15). Asimismo, 
supone la presencia del emisor, el signo y el receptor. No obstante, en el desarrollo del proceso, es posible que el emisor o el receptor falten, pero de ninguna manera el signo, ya que siempre está presente como elemento portador del significado, como expresión formal de un contenido: por medio de este, el individuo asocia un sentido a una forma; en consecuencia, la característica fundamental del signo es la de significar, esto es que un individuo lo emita como formalización de un contenido o lo reciba como tal (p. 15).

En la lectura es evidente que el individuo experimenta en todo su esplendor el proceso semiótico descrito; es decir, cuando el lector interactúa con un texto conformado por signos, ya sean imágenes, grafías o sonidos, se ve en la necesidad de asociar una serie de sentidos a dichos signos con el fin de configurar una interpretación posible a lo emitido por el escritor. Si bien el emisor, el signo y el receptor son elementos del proceso semiótico, su presencia y desempeño determina la aparición de variantes. Estas pueden ser: proceso de expresión, de significación, de comunicación, de interacción y de interpretación (Santiago, Castillo y Ruiz, 2005, p. 15). Con el fin de definir la lectura, es preciso indicar que esta se ubica dentro del proceso de interpretación, en el cual el receptor

[...] se constituye en el sujeto activo del proceso, pues "este interpreta como signo algo presente, natural o cultural, aunque no haya sido propuesto como signo por el emisor, que en realidad no actúa como tal emisor, aunque pueda ser soporte de signos". (Bobes, 1989, citado por Santiago, Castillo y Ruiz, 2005, p. 15)

Posteriormente, Santiago, Castillo y Ruiz (2005), siguiendo la perspectiva de Bobes, afirman que la lectura

[...] no es solamente el reconocimiento de unos signos gráficos, o la simple traducción de lo gráfico a lo verbal, o la decodificación de unos símbolos alfabéticos, para convertirse, antes que nada, en un proceso dinámico, en un trabajo de carácter cognitivo, mediante el cual un individuo adelanta una serie de operaciones mentales encaminadas a apropiarse de un texto, que pueden ser de la más diversa índole, dado que no solo buscamos significado en lo escrito o en lo verbal, sino, en lo olfativo, en lo gestual, en lo pictórico; pues [...] en el ámbito cultural, el ser humano vive inmerso en los signos, lo cual lo convierte en constante productor y receptor de estos. (p. 19)

De esta manera, Graile parte de esta definición de lectura para emprender un trabajo de intervención con docentes.

\section{Modalidades de lectura}

Las modalidades de lectura son entendidas desde un enfoque semiótico, donde el sujeto lector utiliza diferentes medios para comprender el sentido del texto. En esta línea, Gunther Kress (2008) propone "una multiplicidad de modos y, en particular, del modo de la imagen (fija y en movimiento), así como de otros modos" (p. 6). Lo anterior, para presentar el cambio del formato, pero este cambio en el texto va a sugerir también un cambio en la recepción de ese mensaje; allí, Calderón y Poveda (2019) hacen un aporte con relación a "los actos variantes e invariantes; donde lo variante es el canal de recepción y lo invariante es el proceso de comprensión que tiene el sujeto del texto" (p. 114). En otras palabras, el sujeto lector puede acceder a los textos mediante diferentes canales de comunicación (auditivos, visuales, etc.), lo cual diversifica las vías de acceso a la comprensión.

Asimismo, se reconoce la escucha como modalidad de lectura, la poesía desde la experiencia estética y la lectura inferencial a partir de un enfoque teórico semiótico, enmarcado en un modelo sociocultural, el cual afirma que "la interacción social promueve la motivación y la habilidad para el uso de la lectura y la escritura en el desempeño 
de actividades productivas" (Braslavsky, 2007 p. 101); es decir, se busca que la lectura sea entendida y desarrollada en contextos reales de acción, que posibiliten comprenderla como un proceso modal, puesto que la escucha y lo estético son categorías que la conforman y que sustentan sus aspectos inferenciales.

De igual manera, se tendrán en cuenta otras modalidades presentes en los espacios en los que los estudiantes y docentes confluyen, con el fin de integrar este proceso, constructor de conocimiento, de manera significativa en la vida de los participantes, transformando así las prácticas pedagógicas y la experiencia estética y disciplinar con la lectura. Por lo anterior, se plantean tres miradas sobre la lectura:

En primer lugar, la lectura auditiva, donde se postula la escucha como una modalidad de lectura, en cuanto se comprende la complejidad de los procesos que pone en marcha una persona cuando escucha un mensaje, esto a partir de la propuesta de Beuchat (1989), quien define oír como "la recepción física de las ondas sonoras a través del oído", y escuchar como "la capacidad de recibir y responder al estímulo físico y utilizar la información captada a través del canal auditivo" (p. 2). En esta medida se asocia al proceso de lectura en cuanto se estima que leer, como lo plantea Calderón et al. (2014), involucra múltiples aspectos semióticos, estéticos, comunicativos, afectivos, intelectivos y situacionales que se ponen en marcha según el canal de recepción que emplee el sujeto para su lectura, mismo que se adecua al formato de texto que le sea presentado.

En segundo lugar, la lectura como experiencia estética es vista desde el encuentro del lector con el texto, un encuentro íntimo, único e irrepetible, que lleva consigo una transformación de lector, tal y como lo plantea Larrosa (2003):

Pensar la lectura como formación implica pensarla como una actividad que tiene que ver con la subjetividad del lector: no solo con lo que el lector sabe sino con lo que es. Se trata de pensar la lectura como algo que nos forma (o nos de-forma o nos transforma), como algo que nos constituye o nos pone en cuestión con aquello que somos. (pp. 25-26)

Es decir, la lectura tiene una implicación directa en la subjetividad de quien lee, no se trata de leer por acceder a cierta información, sino que lo que se intenta defender es la lectura desde el placer, el gusto $y$, por ende, la experiencia, aquello que permite el deleite del texto literario y el alimento del espíritu de quien lee.

En tercer lugar, se encuentra la posibilidad de usar la inferencia para llegar a la comprensión de textos expositivos. Para ello, es necesario que estas sean entendidas como "representaciones mentales que el lector construye, al tratar de comprender el mensaje leído, sustituyendo, añadiendo, integrando u omitiendo información del texto" (León, 2003 , p. 24). En este sentido, gracias a las inferencias se ponen en marcha una serie de operaciones mentales que, por un lado, demandan esfuerzos $y$ transforman al lector en un sujeto activo; y por otro, permiten construir una visión propia del texto. Por esta razón, esta modalidad ofrece la posibilidad de cambiar la visión tradicional de la lectura, por una en donde se valoran los esfuerzos del lector por llegar a la comprensión.

\section{Metodología}

A partir de lo expuesto, el presente reporte de caso pretende defender la siguiente idea: los docentes de una institución educativa del suroccidente de Bogotá presentan una concepción tradicional de la lectura, la cual se ve reflejada en su práctica pedagógica. Esta situación requiere de una actualización teórica enfocada en tres modalidades de lectura: la escucha, la estética y la inferencial.

Ahora bien, el enfoque metodológico se ubica en el paradigma interpretativo y un enfoque cualitativo, el cual permite entender la realidad social como distinta a la natural, desde una perspectiva 
subjetiva, donde el investigador forma parte de la situación que se investiga. Del mismo modo, la observación etnográfica, la contextualización, el análisis de documentos e instrumentos permiten realizar una triangulación a partir de la realidad misma, siendo un paradigma que busca comprender e interpretar la vida social, desde una reflexión, una profundización y un detenimiento ante lo que muchas veces se naturaliza en la escuela (Bonilla y Rodríguez, 1997).

Para desarrollar la propuesta de intervención, se eligió el taller como estrategia pedagógica, puesto que, según Rodríguez (2012), "el taller facilita la apropiación de conocimientos, habilidades o destrezas a partir de la realización de un conjunto de actividades desarrolladas entre los participantes" (p. 16). En la tabla 1 se detalla la organización de los talleres.

De acuerdo con la tabla 1, el taller 1 consistió en un diagnóstico para determinar las concepciones de lectura que manejaban los docentes. De este diagnóstico, se obtuvo que la concepción se limita a lo lingüístico, dejando de lado otros canales de recepción que posibilitan el proceso lector.
Para este taller se utilizó la tabla 2. Posteriormente, se dividió el grupo en tres subgrupos, con el fin de dar inicio a la indagación de saberes previos sobre las tres modalidades de lectura propuestas.

Por su parte, los talleres 2, 3 y 4 estuvieron enfocados a la actualización teórica de los docentes. El taller 2 se centró en aportar información reciente sobre la escucha como modalidad de lectura, para ello se utilizaron audiolibros con el objetivo de reconstruir las historias narradas y así dar cuenta del proceso lector. El taller 3 brindó herramientas para considerar la lectura desde la experiencia estética, para ello se recitaron poemas y se avanzó en la indagación de las experiencias personales de los docentes. El taller 4 propuso la inferencia en textos expositivos como una herramienta válida para considerar al proceso lector en el aula. Finalmente, el taller 5 evaluó los aportes de cada una de las tres modalidades a partir de discusiones y exposiciones de experiencias en el aula, y se obtuvo que la actualización teórica fue significativa para los docentes participantes de la intervención.

Tabla 1. Organización de talleres

\begin{tabular}{|c|c|c|}
\hline No. & Nombre del taller & Objetivo \\
\hline 1 & ¿Qué es la lectura? & $\begin{array}{l}\text { - Identificar las concepciones de los docentes sobre la lectura. } \\
\text { - Identificar la metodología empleada por los docentes a la hora de } \\
\text { trabajar diferentes tipos de textos en el aula. }\end{array}$ \\
\hline 2 & La escucha como modalidad de lectura & Comprender la escucha como otra modalidad de lectura. \\
\hline 3 & Llegó la poesía a buscarme & $\begin{array}{l}\text { - Dar a conocer a las docentes pautas para la lectura de poemas en el } \\
\text { aula de clase, a partir del placer estético. }\end{array}$ \\
\hline 4 & Utilizando la inferencia en textos expositivos & - Emplear la inferencia en la lectura de textos expositivos. \\
\hline 5 & Evaluación de saberes & $\begin{array}{l}\text { - Evaluar y socializar los objetivos alcanzados frente a las intervencio- } \\
\text { nes sobre las tres modalidades de lectura. }\end{array}$ \\
\hline
\end{tabular}

Fuente: elaboración propia.

Tabla 2. Concepciones de lectura

\begin{tabular}{ll}
\hline \multicolumn{1}{c}{ Conocimientos sobre... } & ¿Qué sé? \\
\hline La lectura & \\
\hline Las modalidades de lectura & \\
\hline
\end{tabular}

Fuente: elaboración propia. 


\section{Corpus de estudio}

La propuesta se desarrolló con 15 docentes de un colegio ubicado en el suroccidente de la ciudad de Bogotá, quienes se desempeñaban en diferentes grados en el área de Humanidades. Asistieron a cinco talleres sobre las modalidades de lectura, los cuales arrojaron una serie de datos que serán analizados a continuación.

\section{Análisis de los resultados}

En este apartado se presentan los resultados obtenidos en la intervención con docentes de diferentes grados del área de humanidades, de tal manera que se jerarquizan según el objetivo planteado. Por consiguiente, se desarrollarán las categorías de lectura y modalidades de lectura.

\section{¿Qué es la lectura?}

El primer taller tuvo como finalidad indagar sobre las concepciones que tienen los docentes sobre la lectura, lo cual permitió diagnosticar, planear y diseñar los talleres orientados a la actualización del profesorado en su práctica pedagógica. En este sentido, en la categoría de lectura se obtuvieron los resultados que se presentan en la figura 1.

Según estos resultados, la mayoría de docentes la definieron desde una perspectiva lingüística, limitándose al sistema alfabético, al afirmar que se refiere a "textos que deben ser decodificados" para obtener cierta información y comprender el mensaje que transmiten. Otros apuntaron a una perspectiva cognitiva entendiéndola como proceso que permite acercarse y ampliar conocimientos. Finalmente, algunos afirmaron que la lectura es el "arte de comprender el mundo", esta es quizá la visión más amplia. De manera que es desde allí que se busca forjar los conceptos de imaginación y observación, pues ellos reconocieron las imágenes como textos que pueden ser leídos, sin nombrar en ningún momento el proceso de decodificación. Por lo anterior, se evidencia que la lectura sigue siendo entendida como un proceso lingüístico que implica la decodificación de los signos de un idioma, lo cual indica que la perspectiva pragmática y semiótica queda fuera de dicha concepción.

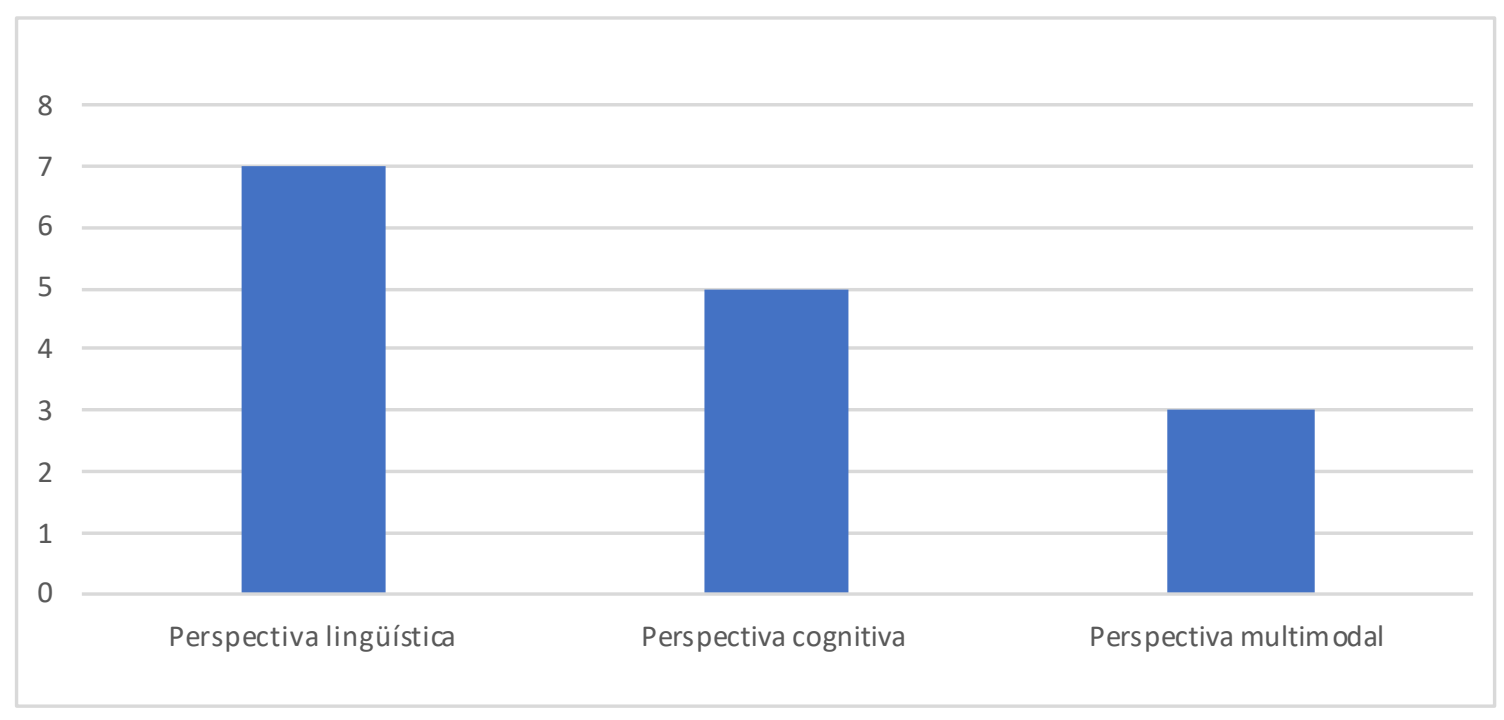

Figura 1. Concepciones sobre lectura

Fuente: elaboración propia. 


\section{Modalidades de lectura}

Al preguntar a los docentes sobre esta segunda categoría, se obtuvieron los resultados que se ilustran en la figura 2.

Las concepciones docentes sobre las modalidades de lectura fueron muy variadas. Hubo un grupo que las definió desde las superestructuras, atendiendo únicamente a la forma, es decir que estas no se daban en la relación del lector con el texto, sino en el texto mismo. Otros las definieron desde las formas de leer: en voz alta, grupal y mental; para este grupo, la modalidad ya se trasladaba a la acción de lector. Los demás las entendieron a partir de los tres niveles de lectura (literal, inferencial, crítico). Por último, dos docentes argumentaron no saber. Sus respuestas evidenciaron un desconocimiento parcial de lo que son las modalidades de lectura, puesto que atendieron únicamente a referentes textolingüísticos, dejando de lado al estudiante y sus diferentes canales de recepción.

Por lo anterior, durante la intervención se buscó movilizar sus conocimientos a partir de las experiencias, de tal suerte que al llevar audiolibros, poemas y un artículo científico a los talleres, no solo se vieron motivados, sino también interesados, por cuanto experimentaron un sistema de comprensión diferente al que ellos ya habían trabajado antes en el aula. Por último, cabe resaltar que los docentes se mostraron sorprendidos por las posibilidades que se tenían desde el trabajo de las inferencias en los textos expositivos, la poesía como una estrategia para desarrollar la recepción estética del texto, y la escucha como un canal de comprensión de lectura alterno.

\section{Discusión}

Para consolidar la discusión se retomarán las dos categorías de análisis contempladas: lectura y modalidades de lectura. Se revisó el grado de asimilación de estas por parte de los docentes, no solo durante los talleres, sino en sus clases, las cuales fueron monitoreadas. La figura 3 presenta dos gráficas en las que se comparan las categorías antes y después de la intervención.

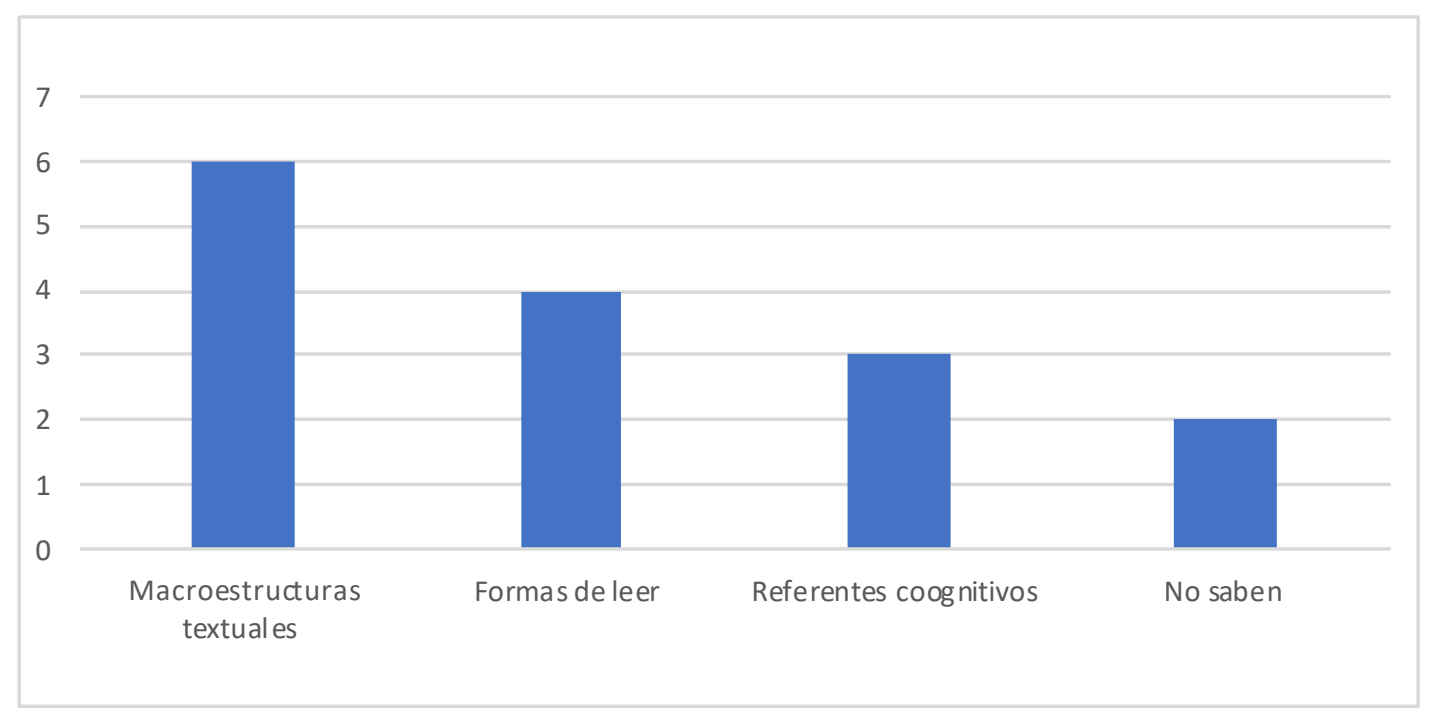

Figura 2. Concepciones sobre las modalidades de lectura

Fuente: elaboración propia. 
Esta figura evidencia el avance significativo de los docentes frente a la apropiación de una perspectiva multimodal de la lectura, ya que, en relación con el diagnóstico, once docentes optan por esta perspectiva, tomando distancia de los enfoques tradicionales y teniendo un nuevo fundamento para el diseño de sus unidades didácticas. Este último aspecto representa una potencia en la formación del profesorado, por cuanto se cualifican las prácticas que el docente usualmente lleva a cabo en el aula, ya que en la evaluación ellos manifestaban que en ocasiones llevaban videos o canciones al aula, pero que desconocían los procesos de fondo que podrían fortalecer al cambiar el formato del texto alfabético por otros sistemas de comprensión.

Por su parte, la figura 4 evidencia que los docentes apropiaron el término (modalidades de lectura), entendiendo que no hace referencia a la superestructura, sino a las diferentes formas de leer que se pueden mediar por los canales de recepción del lector. Además, los que presentaban desconocimiento del tema, ahora apropiaron el término que se construyó a lo largo de la intervención. Es importante añadir que muchos de ellos solamente recurrían a textos alfabéticos para trabajar la lectura; luego de los talleres, en el momento de la evaluación, manifestaron que los estudiantes se veían muy interesados cuando ellos llevaban audiolibros, imágenes, poemas, debates y hasta conversaciones para trabajar la lectura.

En este punto, es importante señalar que cerca del $90 \%$ de los docentes manifestaron haber avanzado en la actualización teórica, puesto que en el último taller de reconstrucción de saberes argumentaron que la lectura puede darse de forma compartida en diferentes escenarios, concepción que se articula con el enfoque sociocultural, el cual se seleccionó para fundamentar el taller.

Además de evidenciar apropiación discursiva acerca del enfoque sociocultural, los docentes reconocieron la experiencia estética como un factor necesario en la evaluación de los textos, al afirmar que esta era crucial a la hora de establecer una conexión entre el lector y el texto. De igual manera, resaltaron el impacto que tuvo llevar las modalidades de lectura al aula, puesto que les permitió

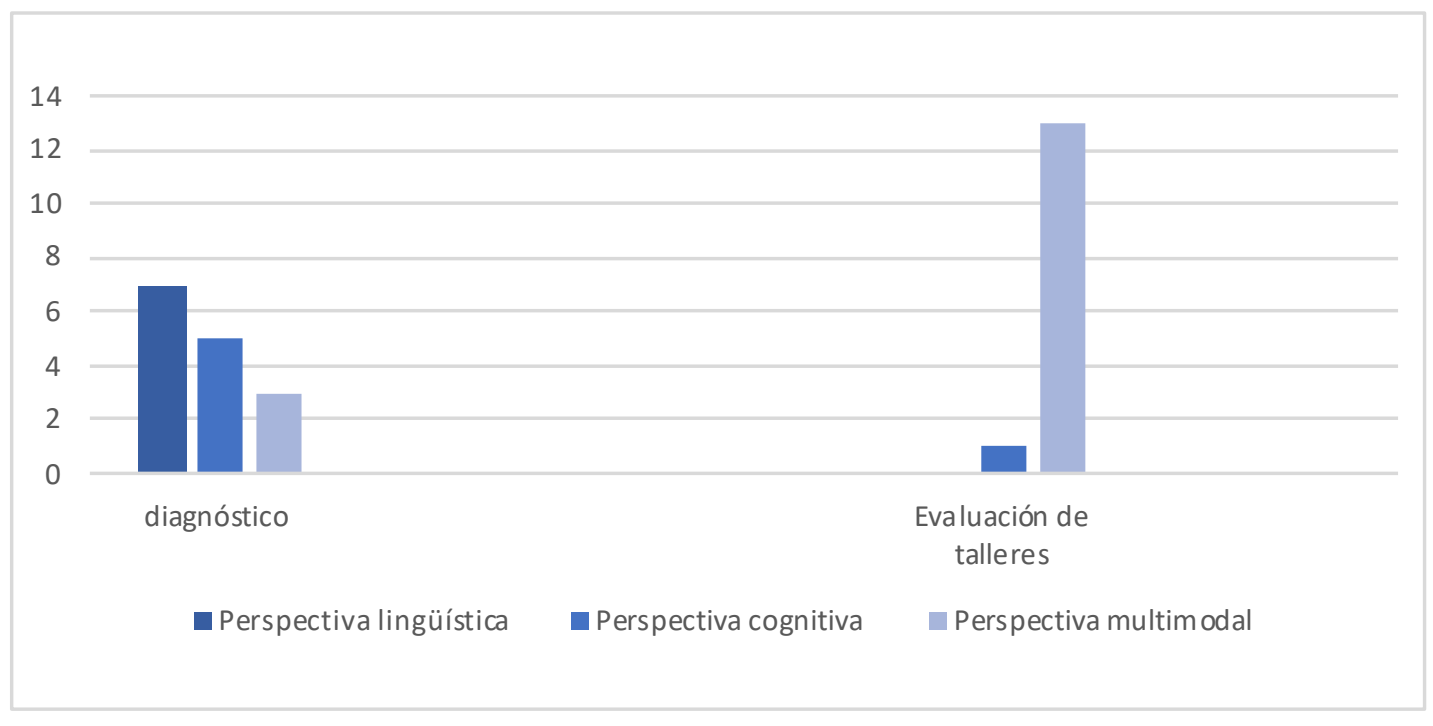

Figura 3. Concepciones sobre la lectura

Fuente: elaboración propia. 


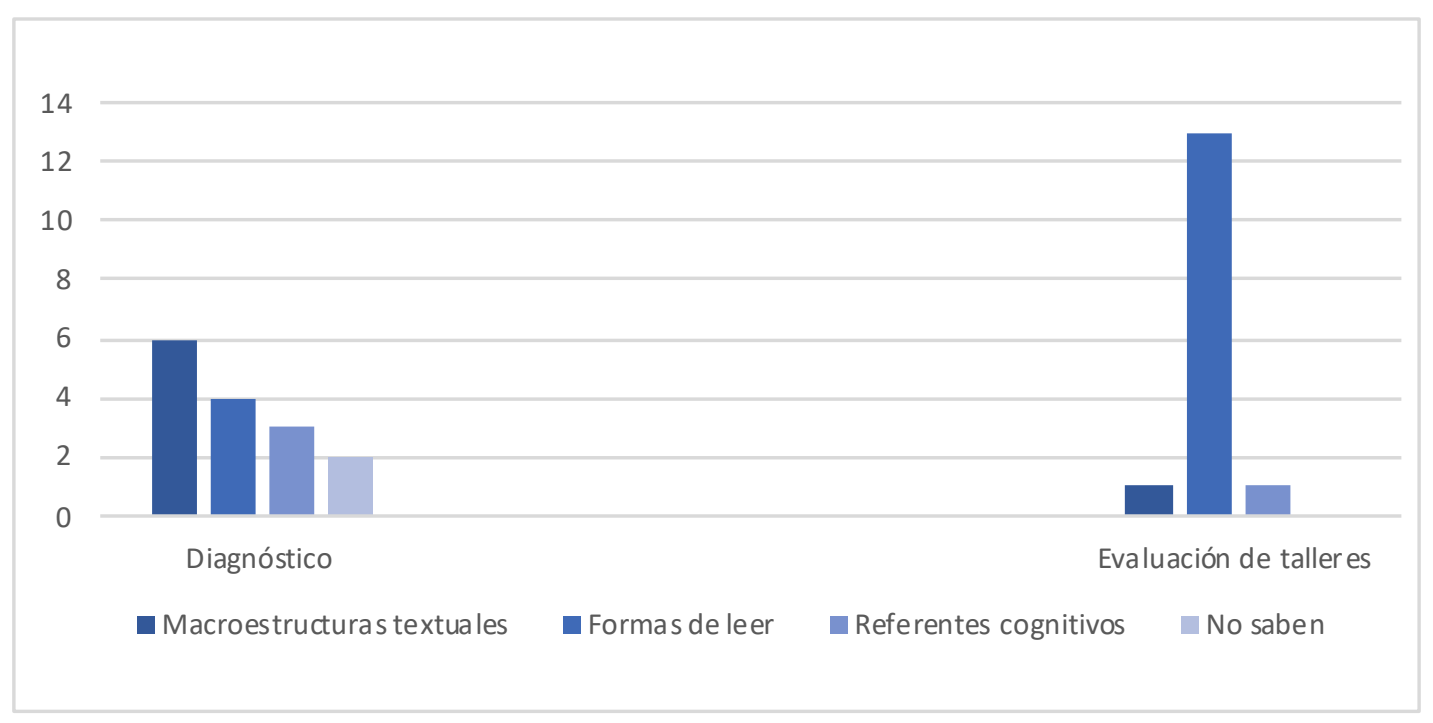

Figura 4. Modalidades de lectura

Fuente: elaboración propia.

desarrollar la lectura de una forma más significativa, tal como lo sugieren (Santiago, Castillo y Ruiz 2005, p. 15), al plantear que la semiótica "brinda al individuo la posibilidad de generar significado y sentido", donde el lector interactúa con un texto conformado por signos, ya sean imágenes, gráficos o sonidos en la construcción de un conocimiento significativo para él.

\section{Conclusión}

Gracias a la triangulación de las concepciones de los docentes, la intervención mediante talleres y el análisis de las categorías (lectura y modalidades de lectura), es posible concluir que: tanto la población participante como los maestrantes iniciaron un proceso de actualización teórica conjunta. Esto se generó gracias a la interacción exitosa entre docentes, teoría y práctica, dada mediante el instrumento de intervención (taller), lo cual exhibe la coherencia con el enfoque sociocultural elegido por Graile para esta propuesta investigativa, el cual expone como premisa que el aprendizaje se da mediante el intercambio de saberes de un grupo de personas ubicadas en un lugar y tiempo determinados.

De manera más específica, se logró actualizar el conocimiento de los actores respecto al concepto de lectura y sus modalidades, afirmación que se sustenta en los resultados presentados. Además, el diseño y aplicación de una propuesta didáctica amplió el espectro de conocimiento y acción, debido a que, en el caso de los maestrantes, se generó la necesidad de poner en práctica la teoría; mientras que para los docentes constituyó una oportunidad de apropiarse de nuevas herramientas, susceptibles de ser modificadas según las necesidades y expectativas de sus estudiantes.

Ahora bien, en relación con el objetivo general, "actualizar teóricamente a los docentes en torno a la perspectiva semiótica de la lectura y tres de sus modalidades: estética, auditiva e inferencial", se puede afirmar que se cumplió a cabalidad, lo cual puede ser corroborado con los resultados analizados y el informe que se ha desplegado a lo largo de este reporte de caso.

Finalmente, sería propicio, para una futura investigación, acompañar el proceso de diseño de 
situaciones didácticas que los docentes implementan en sus clases, a partir de la propuesta de las modalidades de la lectura que se presentó, debido a que, si bien en la rejilla de evaluación se evidenció el avance de los docentes en relación con su constructo teórico, es necesario instruir directamente en este trabajo.

\section{Reconocimientos}

El grupo académico de investigación en lectura Graile surge de las diversas inquietudes en torno a los procesos de enseñanza y aprendizaje sobre la lectura como trabajo investigativo del Seminario de Líneas de Investigación I, en la Maestría en Pedagogía de la Lengua Materna, de la Universidad Distrital Francisco José de Caldas, desarrollado durante el primer semestre de 2019.

\section{Referencias bibliográficas}

Bernal Leongómez, J. (1984). Tres momentos estelares en lingüística. Bogotá: Instituto Caro y Cuervo.

Beuchat, C. (1989). Escuchar: el punto de partida, el punto de partida. Lectura y Vida, Revista Latinoamericana de Lectura, (3), 20-25.

Bonilla, E. y Rodríguez, P. (1997). Más allá del dilema de los métodos. La investigación en Ciencias Sociales. Santafé de Bogotá: Editorial Norma.

Braslavsky, B. (2007). Nuevos tiempos y modos en el aprendizaje y la enseñanza de la lectura y la escritura. En ¿Primeras letras o primeras lecturas? Una introducción a la Alfabetización Temprana (pp. 93110). México: Fondo de Cultura Económica.

Calderón, D. y Poveda, D. (2019) La escucha como modalidad de lectura en la consolidación de una trayectoria hipotética para su aprendizaje. [Tesis de maestría]. Universidad Distrital Francisco José de Caldas,
Bogotá, Colombia. Recuperado de http://repository. udistrital.edu.co/bitstream/11349/23086/1/PovedaVargasDylanFerney2020.pdf

Calderón, D., Soler, S., Borja, M., Muñoz, G., Rojas, G. y Medina, G. (2014). Referentes curriculares con incorporación de tecnologías para la formación del profesorado de lenguaje y comunicación en y para la diversidad. Bogotá: Universidad Distrital Francisco José de Caldas.

De Saussure, F. (1974). Curso de lingüística general. Buenos Aires: Losada.

Halliday, M. (1998). El lenguaje como semiótica social. Bogotá: Fondo de Cultura Económica.

Hymes, D. (1972). Dirección en sociolingüística: la etnografía de la comunicación. Nueva York: Rinehart \& Winston.

Kress, G. (2008). El alfabetismo en la era de los nuevos medios de comunicación. Londres: Routledge.

Larrosa, J. (2003). La experiencia de la lectura. México: Fondo de Cultura Económica.

León, J. (2003). Conocimiento y discurso. Claves para inferir y comprender. Madrid: Ediciones Pirámide.

Rodríguez, M. E. (2012). El taller: una estrategia para aprender, enseñar e investigar. En S. Soler (comp.), Lenguaje y educación: perspectivas metodológicas y teóricas para su estudio (pp. 13-43). Bogotá: Universidad Pedagógica Nacional, Universidad Distrital Francisco José de Caldas, Universidad del Valle. Recuperado de https://www.academia. edu/20109717/Lenguaje_y_Educaci\%C3\%B3n_ Perspectivas_metodol\%C3\%B3gicas_y_te\%C3\%B3ricas_para_su_estudio

Santiago, A., Castillo C. y Ruiz, J. (2005). Lectura, metacognición y evaluación. Bogotá: Alejandría Libros.

Vygotsky, L. (1977). Pensamiento y lenguaje. Buenos Aires: Pléyade. 